\title{
95. The Origin of Natural Monument, Scarlet Crucian Carp (Hibuna) in the Harutori Lake, Kushiro, Hokkaido, Japan*)
}

\author{
By Yoshio OJIMA \\ Department of Biology, Faculty of Science, \\ Kwansei Gakuin University, Nishinomiya
}

(Communicated by Sajiro Makino, M. J. A., Dec. 14, 1987)

In 1979, Ojima et al. reported the origin of the gold-fish, on the basis of comparative investigations of the chromosomes of the gold-fish and Funa varies from Japan and China, use being made of the current C-banding technique and electrophoretic patterns of the muscle protein.

On the basis of the above findings, it can be stated with certainty that the Chinese Funa, Carassius auratus auratus and the gold-fish were fairly identical with each other.

"Scarlet Crucian Carp" (Hibuna) in the Harutori Lake of Kushiro, Hokkaido was designated as a Natural Monument of Japan in 1937. Since then, however, no one had the opportunity to closely examine the origin of this special Hibuna because of its protected status. We knew only as a historical fact that three thousand gold-fish had been implanted in this lake in 1916.

The present study was undertaken to deal cytogenetically with the origin of the Hibuna, in comparison with the Japanese genus Carassius and the gold-fish.

Materials and methods. Four Hibunas including one with slightly greater body breadth (Sample 1) and three with gently-sloping average body depth (Sample 2, a-c) from the Harutori Lake were provided for the study.

The fin culture method for chromosome preparations was applied to all of them. The Giemsa C-banding technique was applied to them for the chromosome analysis.

Results and remarks. 1) Sample 1 showing slightly greater body breadth (Fig. 1). The somatic cells of Sample 1 showed at metaphase 100 chromosomes as a diploid number. In all varieties so far studied the complement consisted of 6 pairs of metacentrics, 18 pairs of submetacentrics, and 26 pairs of teloor subtelocentrics (Fig. 2). The karyotype of Sample 1 was characterized by a pair of marker chromosomes with deeply stained C-bands on the short arms of the second largest submetacentrics among 100 chromosomes.

Referring to the results of karyotypic studies in the gold-fish (Ojima et al., 1979) (Fig. 3), it was apparent that the chromosomes of the Sample 1 "Hibuna" were fairly identical both numerically and morphologically with those of the gold-fish, the demarcation between them being quite impossible. It was clear from these results that Sample 1 "Hibuna" was female.

Fig. 3 is a female karyotype of the gold-fish with a pair of marker chromosomes. $2 n=100$.

2) Sample 2(a-c) showing gently-sloping body breadth (Fig. 4). Three

*) This work was supported by a grant-in-aid of the Science Research Promotion Fund from the Japan Private School Promotion Foundation. 

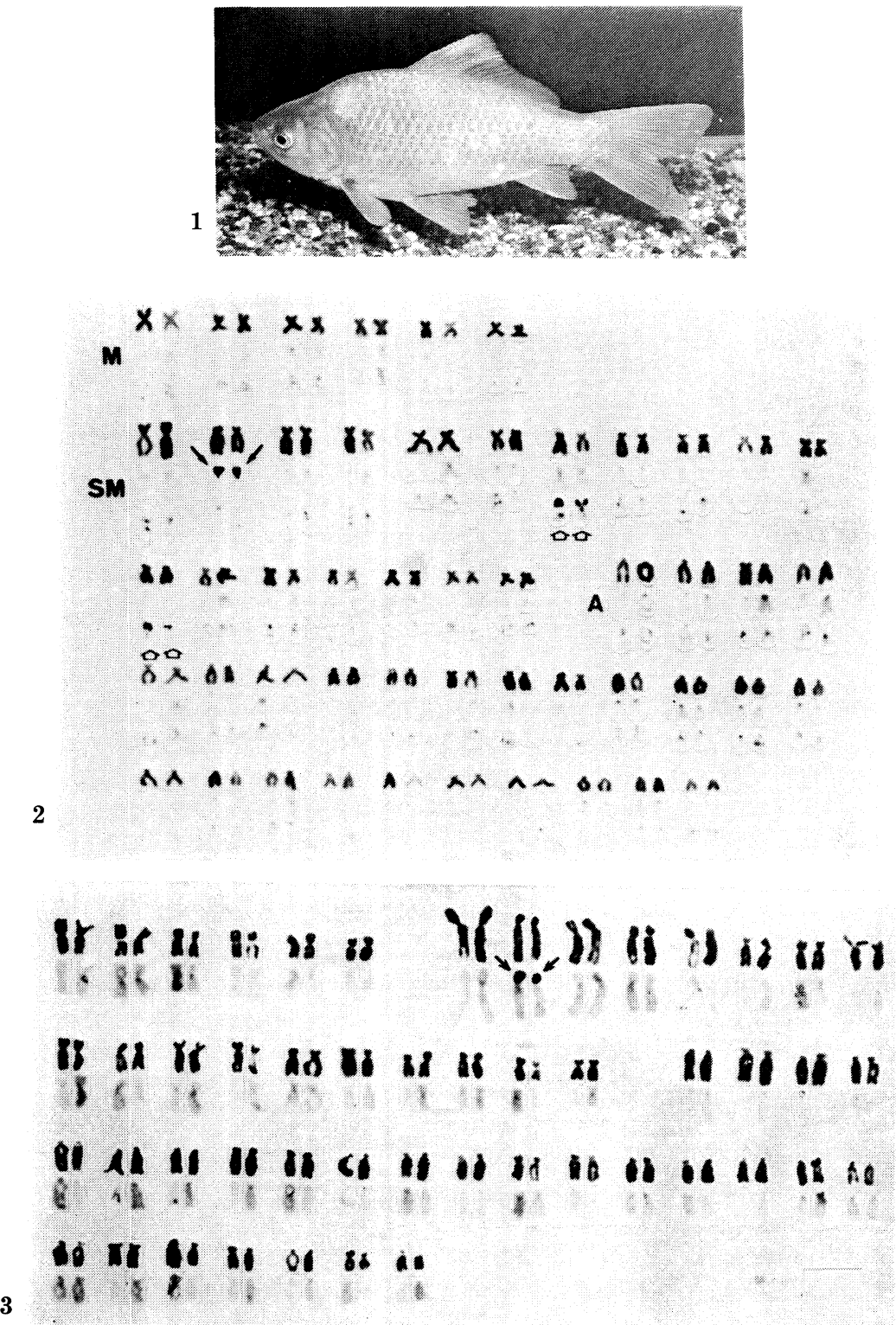

Figs. 1-3. 1: Sample 1 (diploid Hibuna) showing slightly greater body breadth. 2: Female karyotype of diploid Hibuna with a pair of marker chromosomes. $2 n=100$. 3: Female karyotype of the Gold-fish with a pair of marker chromosomes. $2 n=100$.

"Hibunas" of Sample 2 showed" at metaphase 154 chromosomes as a triploid number, carrying a pair of markers characterized by outstanding C-bands on the short arms of the second largest submetacentrics and C-banded three microchromosomes (Fig. 5).

Fig. 6 was the karyotype of the Ginbuna, Carassius auratus langsdorfi, which was characterized by a pair of marker chromosomes with deeply stained 


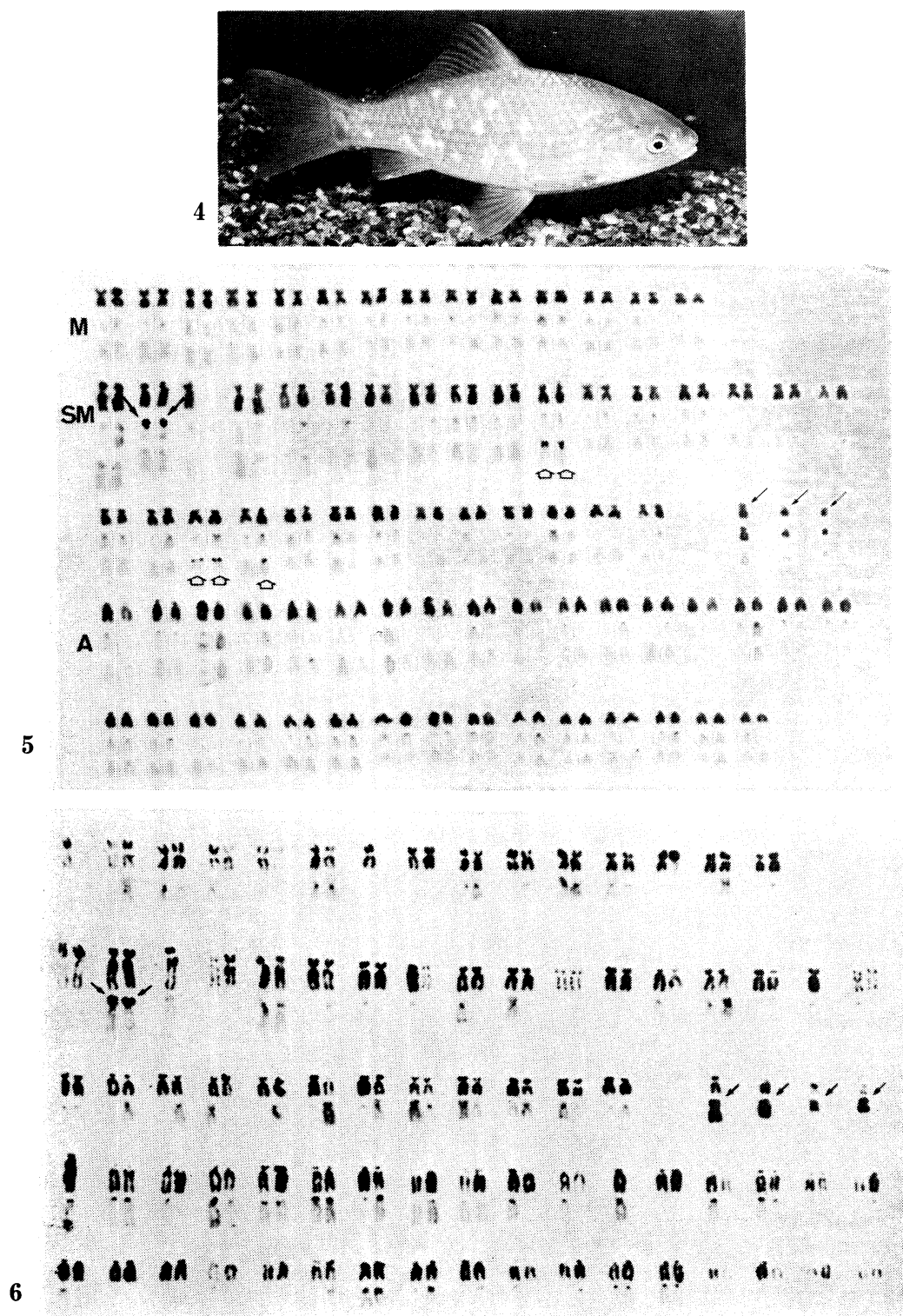

Figs. 4-6. 4: Sample 2 (triploid Hibuna) showing gently-sloping body breadth. 5: Female karyotype of triploid Hibuna carrying a pair of marker chromosomes and C-banded three micro-chromosomes. $2 n=154$. 6 : Karyotype of Ginbuna (C. $a$. langsdorfii) with a pair of marker chromosomes and four C-banded microchromosomes. $2 n=154$.

C-bands on the short arms of the second largest submetacentric chromosomes and 4 micro-chromosomes (Ueda and Ojima, 1978).

As seen in Figs. 5 and 6 , it appeared that there occurred a certain significant relation between the Ginbuna and Hibuna (Sample 2, a-c) with regard to the differential marker chromosomes and the chromosome constitutions. 
Summary. The results clearly show that there are two kinds of Hibuna, diploidy and triploidy, in the Harutori Lake. The diploid Hibuna, 2n=100, show the same chromosome constitution and C-band pattern as the gold-fish. The individuals with triploid chromosomes, $2 n=154$, are the same as those of the Ginbuna (C. a. langsdorfii) in the chromosome constitutions and C-band patterns.

My particular thanks are due to Emeritus Professor Sajiro Makino, M. J. A., for his invaluable advice and revision of the manuscripts.

\section{References}

Ueda, T., and Y. Ojima (1978) : Proc. Japan Acad., 54B, 283-288.

Ojima, Y., T. Ueda, and T. Narikawa (1979): ibid., 55B, 58-63. 